\title{
Proposal for a Breakfast Quality Index (BQI) for children and adolescents
}

\author{
Celia Monteagudo ${ }^{1}$, Alba Palacín-Arce ${ }^{1}$, Maria del Mar Bibiloni ${ }^{2}$, Antoni Pons², \\ Josep A Tur ${ }^{2}$, Fatima Olea-Serrano ${ }^{1, *}$ and Miguel Mariscal-Arcas ${ }^{1}$ \\ 'Department of Nutrition and Food Science, University of Granada, Campus de Cartuja s/n, E-18071 Granada, \\ Spain: ${ }^{2}$ Research Group on Community Nutrition and Oxidative Stress, University of the Balearic Islands, Palma \\ de Mallorca, Spain
}

Submitted 2 January 2012: Final revision received 2 May 2012: Accepted 15 May 2012: First published online 5 July 2012

\begin{abstract}
Objective: To propose and apply an instrument to assess the breakfast quality of children and adolescents in the Mediterranean area.

Design: Randomized, cross-sectional survey of breakfast consumption using a validated semi-quantitative FFQ administered at school by trained dietitians between Tuesday and Friday. A Breakfast Quality Index (BQI) score was developed, assigning a positive value to the consumption of cereals, fruit, vegetables, dairy products, MUFA, Ca and compliance with energy recommendations, and to the absence of SFA and trans-rich fats. Data were analysed by Student's $t$ test and ANOVA.

Setting: Schools in Granada and Balearic Islands (Spain).

Subjects: All schoolchildren ( $n$ 4332) aged $8-17$ years at randomly selected and representative schools between 2006 and 2008, stratified by age and sex.

Results: Breakfast was not consumed by $6 \cdot 5 \%$ of participants. BQI score was highest for children aged $7-9$ years and decreased with age $(P=0 \cdot 001)$. Females scored higher in all age groups. The lowest score was in males aged 14-17 years and the highest in females aged $7-9$ years $(P=0 \cdot 006)$.

Conclusions: The proposed BQI appears useful to estimate the breakfast quality of schoolchildren and to form a basis for nutrition education.
\end{abstract}

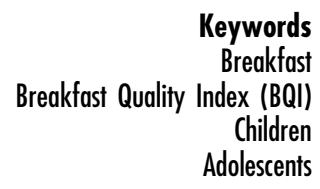

The Mediterranean diet is characterized by the use of certain food items with known beneficial effects on health. The relationship between adherence to the Mediterranean dietary pattern and reduced mortality or lower incidence of major chronic diseases has been widely studied across multiple epidemiological analytical studies ${ }^{(1-6)}$. A key feature of the Mediterranean dietary pattern is the consumption of an adequate breakfast, which can be defined as the first meal of the day, taken before or at the start of daily activities with an energy content that meets $20-25 \%$ of total daily energy needs ${ }^{(7-9)}$, and which includes dairy products, cereals, fruit and healthy fats. Among both adults and adolescents, the skipping of breakfast has been associated with smoking, infrequent exercise, low educational level, frequent alcohol use and high $\mathrm{BMI}^{(10-13)}$. It has been reported that the failure to consume an adequate breakfast contributes to poor school performance and to dietary deficits that are rarely compensated for at other meals and may lead to a higher consumption of energy-dense snacks later in the day ${ }^{(14-20)}$.

Nutrition education is known to be important to promote healthy breakfast habits in young people, but there remains a need for a reliable instrument to evaluate breakfast quality ${ }^{(21)}$. The aim of the present study was to assess the breakfast quality of children and adolescents in the Mediterranean area and to propose a useful instrument to estimate the quality of breakfast in this setting.

\section{Materials and methods}

The study was a population-based, cross-sectional nutritional survey carried out in Granada (southern Spain) and the Balearic Islands (north-eastern Spain) between 2006 and 2008.

The population sample comprised 4332 children and adolescents aged 8-17 years registered in school censuses of Granada (73.6\%) and the Balearic Islands (26.4\%). The sampling technique included stratification according to age and sex. Municipalities in Granada and the Balearic Islands were the primary sampling units, and individuals within the schools of these municipalities were the final sampling units. Interviews were conducted in the schools. 
Table 1 Breakfast Quality Index (BQI): items included and scoring (points awarded)

\begin{tabular}{lcc}
\hline Items included & Yes & No \\
\hline 1. Cereals and derivatives (bread, breakfast cereals, biscuits, bakery products) & +1 & 0 \\
2. Fruit and vegetables (fruit, fruit juice, vegetables) & +1 & 0 \\
3. Dairy products (whole and semi-skimmed milk, milk shake, yoghurt, cheese) & +1 & 0 \\
4. Foods rich in simple sugars (sugar, jam, honey) $<5 \%$ of total daily energy & +1 & 0 \\
5. MUFA-rich fats (olive oil, vegetable oil) & +1 & 0 \\
6. MUFA:SFA > median & +1 & 0 \\
7. Compliance with energy intake recommendations (20-25\% of total daily energy) & +1 & 0 \\
8. Cereals + fruit + dairy product in the same meal & +1 & 0 \\
9. Ca (200-300 mg) & +1 & 0 \\
10. Absence of SFA and trans-rich fats (butter, margarine) & +1 & 0 \\
\hline
\end{tabular}

The frequency of consumption of foods was investigated by means of a validated semi-quantitative $\mathrm{FFQ}^{(22-27)}$, classifying the consumption frequency over the previous 12 months as: never, less than once/month; once/month; 2-3 times/month; 1-2 times/week; 3-4 times/week; 5-6 times/week; once/d; 2-3 times/d; 4-5 times/d. This FFQ is divided into five sections corresponding to five meal times (early morning, mid-morning, mid-day, midafternoon, evening) and each section contains foods usually consumed in Mediterranean countries. Besides data on the total daily intakes of nutrients, the present analysis focused on sections 1 and 2 of the questionnaire (for breakfast and mid-morning snack), which included the following items: bread, breakfast cereals, biscuits, fruit, fruit juice, vegetables, milk, cheese, yoghurt, olive oil, butter, margarine, sugar, jam, honey and bakery products. Results were expressed as $\mathrm{g} / \mathrm{d}$. The mean portions consumed by the study population were estimated according to the usual domestic measurements or, in some cases, the amount generally considered an average portion in Spain $^{(28,29)}$.

Participants were identified by a six-digit number to preserve their anonymity. Sociodemographic data were gathered on sex, age, school year and educational centre. Questionnaires were administered at the school or in the young person's home by a trained dietitian between Tuesday and Friday. The dietary software program NOVARTIS-DIETSOURCE version $1 \cdot 2$ was used to convert foods into nutrients ${ }^{(30)}$.

\section{Breakfast Quality Index}

The proposed index considers the foods reported (in the FFQ) to be consumed between waking and the end of the mid-morning break (i.e. $\sim 10.30$ hours) and their nutrient content. Intakes were evaluated according to previously published guidelines for the Mediterranean $\operatorname{diet}^{(7,18,31-33)}$, scoring one point each for the consumption of cereals, fruit/vegetables, dairy products and MUFA fats, one point for the intake of simple sugars $<5 \%$ of total daily energy consumption, one point for energy intake 20-25\% of total daily energy intake, one point for intake of $200-300 \mathrm{mg}$ of $\mathrm{Ca}$, one point for MUFA:SFA ratio above the median for the population, one point for the consumption of cereals, dairy products and fruit/vegetables together in one meal, and one point for the non-consumption of foods rich in SFA or trans fats. Scores on the proposed index scale range from 1 to 10 (Table 1 ).

The statistical software package SPSS for Windows version 17 (SPSS Inc.) was used for the statistical analysis. Because application of the Kolmogorov-Smirnov test showed the data to be normally distributed, ANOVA was used to compare the intakes of nutrients among age groups and to analyse the relationships between energy and macronutrient intakes and BQI score (in tertiles). Student's $t$ test was used to compare between the sexes. $P<0.05$ was considered significant in all analyses.

The study complied with the guidelines in the Declaration of Helsinki, and all procedures were approved by the ethics committees of the University of Granada and the University of the Balearic Islands. Written informed consent was obtained from all children and their parents or guardians.

\section{Results}

Questionnaire results from the 4332 children revealed that $6.5 \%$ of them did not consume breakfast. The proportion of non-breakfasters was highest among the 14-17-year-olds $(13.0 \%)$ and especially among the females in this age group (16.5\% of females $v \cdot 9 \cdot 3 \%$ of males, $P<0 \cdot 001$ ). Results for the 281 non-breakfasters were excluded from the analyses.

Table 2 shows the mean estimated intakes of energy and the nutrients considered in the BQI by age group and sex, based on the FFQ data on breakfast and total intakes. All intakes decreased significantly with age $(P<0 \cdot 001)$, with the exception of MUFA:SFA $(P<0 \cdot 05)$. Boys had higher intakes $(P<0.05)$ of SFA and cholesterol and girls had higher $(P<0 \cdot 001)$ MUFA:SFA. The estimated mean breakfast energy consumption of the whole sample represented $25 \cdot 02 \%$ of the total daily energy intake. The ratio between energy intake at breakfast and total energy intake was higher in the 7-9-yearsolds than in the other age groups $(P<0 \cdot 001)$ but did not differ between the sexes $(P=0 \cdot 117)$. Each breakfast nutrient analysed represented between about one-fifth and one-third of its total daily intake, with the exception of protein (below one-fifth) and $\mathrm{Ca}$ (above one-third).

The mean BQI score of the whole population was 5.64 (SD 1.60). Stratification of the BQI scores into tertiles 
showed that $77 \cdot 7 \%$ of the whole population had a score of $4-7,13 \cdot 6 \%$ a score $\geq 8$, and $8 \cdot 7 \%$ a score $\leq 3$. Table 3 shows the energy intake at breakfast as a percentage of total daily energy and reports the contribution of each nutrient to the breakfast energy intake, grouped by BQI tertile. All food/nutrient groups showed significant differences among tertiles. The highest energy and carbohydrate intakes and lowest protein and fat intakes (expressed as percentages of breakfast energy and total energy) were observed for BQI score $\geq 8$, and stepwise regression analysis revealed that bakery products, bread, biscuits and breakfast cereals contributed $95 \%$ of the energy intake among those in the third BQI tertile.

Figure 1 depicts the significant reduction in BQI score with age $(P=0 \cdot 006$, Spearman test). A significant gender difference in BQI score was found for all age groups ( $P=0 \cdot 006, t$ test), with the boys aged 14-17 years showing the lowest score (mean $5 \cdot 28$ (SD 1.55)) and the girls aged 7-9 years the highest score (mean 5.92 (sD 1.60)). The interaction of age and sex had a significant effect on BQI score $(P=0 \cdot 018$, two-factor ANOVA).

\section{Discussion}

Breakfast consumption by young people has reduced over the past 25 years, with a greater decline among adolescents than in any other age group ${ }^{(9,34)}$. In the present study, $6 \cdot 5 \%$ of the children and adolescents did not take breakfast, and this proportion was higher among the adolescents, in agreement with previous reports ${ }^{(7,35,36)}$. An earlier study of Spanish children and adolescents reported that $4 \cdot 1 \%$ skipped breakfast ${ }^{(37)}$, lower than some estimates of $25 \%$ of young people in other countries ${ }^{(12,38)}$.

A BQI was developed and applied to the $93.5 \%$ of our study population who consumed breakfast. Higher BQI scores were associated with improvements in the relationships of macronutrients to energy intake and with improved Ca intake and MUFA:SFA. The results of stratifying BQI scores into tertiles, associated with significant differences in the intakes of all foods, lead us to propose that the first tertile ( $\leq 3$ points) represents a poor breakfast, the second (4-7 points) a medium-quality breakfast, and the third ( $\geq 8$ points) an adequate breakfast ${ }^{(8,19,21,39)}$. The sole limitation to this categorization in is regard to energy intake, which is above recommendations in breakfasts scoring $\geq 8$ points. According to this classification, significantly more children had a medium-quality (score 4-7) than a poor breakfast (score $\leq 3$ ) until the age of 13 years, but the opposite was true after this age. Further research is warranted to elucidate the reasons for this trend, but a lower parental supervision of breakfast with higher age of the child may play a role ${ }^{(7)}$.

According to various authors, breakfast should supply $20-25 \%$ of total daily energy through the consumption of cereals, fruit and dairy products ${ }^{(7,8)}$, to which we 
Table 3 Relationship of Breakfast Quality Index (BQI) score with energy and macronutrient intakes: schoolchildren aged 8-17 years, Granada and Balearic Islands (Spain), 2006-2008

\begin{tabular}{|c|c|c|c|}
\hline Breakfast intake & $\begin{array}{c}\mathrm{BQI} \leq 3 \\
(n 376 ; 8.7 \%)\end{array}$ & $\begin{array}{c}\mathrm{BQI}=4-7 \\
(n 3365 ; 77 \cdot 7 \%)\end{array}$ & $\begin{array}{c}\mathrm{BQI} \geq 8 \\
(n 591 ; 13.6 \%)\end{array}$ \\
\hline \multicolumn{4}{|l|}{ Energy } \\
\hline Mean $(M J)^{\star \star \star}$ & $2 \cdot 04$ & 3.09 & $3 \cdot 80$ \\
\hline$\%$ Energy $/ \mathrm{d}^{\star \star *}$ & $19 \cdot 19$ & 24.98 & $28 \cdot 40$ \\
\hline \multicolumn{4}{|l|}{ Carbohydrates } \\
\hline Mean $(\mathrm{g})^{\star \star \star}$ & $58 \cdot 58$ & $92 \cdot 20$ & $119 \cdot 82$ \\
\hline$\%$ Energy/breakfast* ${ }^{\star * *}$ & $49 \cdot 09$ & $49 \cdot 61$ & $52 \cdot 41$ \\
\hline \multicolumn{4}{|l|}{ Proteins } \\
\hline Mean $(\mathrm{g})^{\star \star \star}$ & $12 \cdot 80$ & $20 \cdot 08$ & $22 \cdot 43$ \\
\hline$\%$ Energy/breakfast*** & $11 \cdot 87$ & $11 \cdot 22$ & $10 \cdot 12$ \\
\hline \multicolumn{4}{|l|}{ Lipids } \\
\hline Mean $(\mathrm{g})^{\star \star \star}$ & $23 \cdot 71$ & $32 \cdot 71$ & 38.69 \\
\hline$\%$ Energy/breakfast ${ }^{\star \star \star}$ & $41 \cdot 08$ & $39 \cdot 60$ & $38 \cdot 27$ \\
\hline \multicolumn{4}{|l|}{$\mathrm{Ca}$} \\
\hline Mean $(\mathrm{g})^{\star \star \star}$ & $243 \cdot 07$ & $410 \cdot 71$ & $431 \cdot 50$ \\
\hline \multicolumn{4}{|l|}{ MUFA:SFA } \\
\hline Mean $^{\star \star \star}$ & $0 \cdot 86$ & $1 \cdot 16$ & $1 \cdot 48$ \\
\hline
\end{tabular}

Values differed significantly according to $\mathrm{BQI}$ score: ${ }^{\star * \star} P<0.001$.

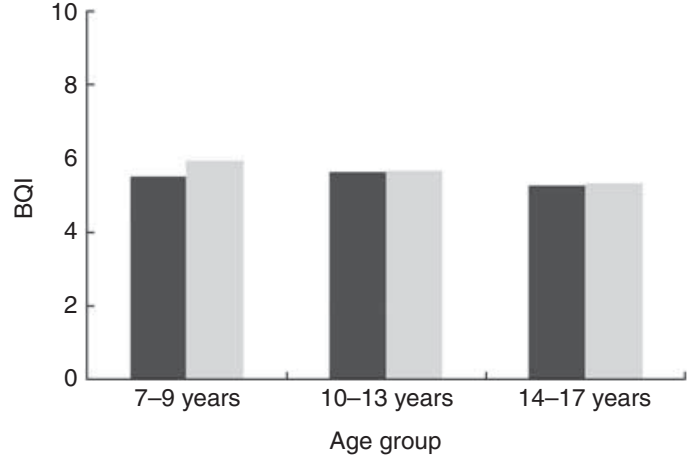

Fig. 1 Breakfast Quality Index (BQI) score by age group and sex ( $\square$, boys; $\square$, girls): schoolchildren aged 8-17 years, Granada and Balearic Islands (Spain), 2006-2008. BQI scores were significantly different between boys and girls in all age groups $(P=0.006)$ and decreased significantly with age $(P=0.001)$

added the intake of simple sugars and MUFA-rich vegetable fats. We also evaluated positively the absence of SFA and trans-rich fats, due to their known relationship with CVD and other chronic non-transmittable illnesses ${ }^{(40-42)}$. MUFA:SFA, widely used as an indicator of the quality of fats in the diet, was also taken into account in our index ${ }^{(26,30,43)}$. The intake of $\mathrm{Ca}$ was also considered, given its special importance in childhood and adolescence, when growth and bone turnover are most intensive ${ }^{(44)}$. It is difficult to meet dietary $\mathrm{Ca}$ recommendations without consuming dairy products, and it has been demonstrated that diets low in Ca and dairy products tend to be deficient in several nutrients ${ }^{(45)}$.

A recent publication on breakfast consumption and physical activity in 9-10-year-olds classified breakfasts as poor or good quality according to the consumption of respectively none/one or two/three of three specific food groups (dairy products, cereal/grain products and fruit) and analysed the relative energy intake ${ }^{(46)}$. The authors did not include mid-morning snacks in their survey, and account was not taken of the breakfast intake of micronutrients (e.g. Ca) or the types of fats consumed.

Glucose and insulin levels fall overnight, explaining the need to consume foods with a high glycaemic index at breakfast as an immediate and important source of energy ${ }^{(47)}$, yielding beneficial cognitive effects and reducing feelings of tiredness ${ }^{(48,49)}$. In our cultural setting, one way to satisfy glucose demands after the nocturnal fast is by consuming sugar, honey or jam, and our survey found a mean breakfast energy intake of $0 \cdot 14(\mathrm{SD} 0 \cdot 10)$ $\mathrm{MJ} / \mathrm{d}$ from simple sugars, which represented about $2 \%$ of total daily energy. This percentage appears consistent with the WHO recommendation that simple carbohydrates should not exceed $10 \%$ of daily energy intake ${ }^{(50)}$. Some studies have shown that breakfast foods with a high glycaemic index are more appetizing for young people and make their consumption of breakfast more likely ${ }^{(51,52)}$. It has also been proposed that the faster delivery of glucose offered by a meal with high glycaemic index may confer benefits on memory functioning ${ }^{(53)}$.

The present breakfast index was developed in a Mediterranean setting, and caution should be taken in extrapolating the results to other regions with different dietary patterns. However, our proposal could serve as a model for developing other reference breakfast indices. These results underline the need for effective nutrition education programmes in schools to encourage young people to follow a balanced diet. Families should also be targeted, given that family meal times are important for the development of healthy dietary habits among children and adolescents ${ }^{(54)}$. High-quality breakfast programmes may improve the dietary status and learning performance of young people and would be especially valuable for those who receive poor nutrition during the rest of the day ${ }^{(55)}$. 
The BQI would be an invaluable instrument in this context, allowing evaluation of the quality of the breakfasts consumed by students and the subsequent correction of any poor habits detected. It can also be applied in adults for the same purposes. The availability of a standardized score would be of major value for epidemiological studies across the Mediterranean and for studies that aim to relate the consumption of breakfast to educational performance or health status, among other variables of interest.

\section{Acknowledgements}

Sources of funding: This study was supported by the Spanish Ministry of Health and Consumption Affairs (Program for Promotion of Biomedical Research and Health Sciences, Projects 05/1276 and 08/1259, and Red Predimed-RETIC RD06/0045/1004); the Spanish Ministry of Education and Science (FPU Program, PhD fellowship to C.M. and M.M.B.); the University of Granada (Postdoctoral Contract to M.M.-A.); the Andalusian Regional Government (grant AGR255); and the Health Department of Granada City Council, Spain. Conflict of interest: The authors state that there are no conflicts of interest. Authors' contributions: M.M.-A., A.P., J.A.T., and F.O.-S. conceived, designed and devised the study; M.M.-A., C.M., M.M.B., J.A.T., A.P.-A. and F.O.-S. collected and supervised the samples, analysed the data and wrote the manuscript; M.M.-A., A.P., J.A.T. and F.O.-S. supervised the study; A.P., J.A.T. and F.O.-S. obtained funding. Acknowledgements: The authors thank Richard Davies for editorial assistance.

\section{References}

1. Fung TT, Rexrode KM, Mantzoros CS et al. (2009) Mediterranean diet and incidence of and mortality from coronary heart disease and stroke in women. Circulation 119, 1093-1100.

2. La Vecchia C (2009) Association between Mediterranean dietary patterns and cancer risk. Nutr Rev 67, Suppl. 1, S126-S129.

3. Martinez-Gonzalez MA, Bes-Rastrollo M, Serra-Majem L et al. (2009) Mediterranean food pattern and the primary prevention of chronic disease: recent developments. Nutr Rev 67, Suppl. 1, S111-S116.

4. Martínez-González MA, García-López M, Bes-Rastrollo M et al. (2011) Mediterranean diet and the incidence of cardiovascular disease: a Spanish cohort. Nutr Metab Cardiovasc Dis 21, 237-244.

5. Sánchez-Villegas A, Delgado-Rodríguez M, Alonso A et al (2009) Association of the Mediterranean dietary pattern with the incidence of depression: the Seguimiento Universidad de Navarra/University of Navarra follow-up (SUN) cohort. Arch Gen Psychiatry 66, 1090-1098.

6. Trichopoulou A, Bamia C \& Trichopoulos D (2009) Anatomy of health effects of Mediterranean diet: Greek EPIC prospective cohort study. BMJ 338, b2337.

7. Aranceta J, Serra-Majem L, Ribas L et al. (2001) Breakfast consumption in Spanish children and young people. Public Health Nutr 4, 1439-1444.
8. Van den Boom A, Serra-Majem L, Ribas L et al. (2006) The contribution of ready-to-eat cereals to daily nutrient intake and breakfast quality in a Mediterranean setting. J Am Coll Nutr 25, 135-143.

9. Giovannini M, Verduci E, Scaglioni S et al. (2008) Breakfast: a good habit, not a repetitive custom. J Int Med Res 36, 613-624.

10. Keski-Rahkonen A, Kaprio J, Rissanen A et al. (2003) Breakfast skipping and health-compromising behaviors in adolescents and adults. Eur J Clin Nutr 57, 842-853.

11. Henríquez Sánchez P, Doreste Alonso J, Laínez Sevillano P et al. (2008) Prevalence of obesity and overweight in adolescents from Canary Islands, Spain. Relationship with breakfast and physical activity. Med Clin (Barc) 130, 606-610.

12. Deshmukh-Taskar PR, Radcliffe JD, Liu Y et al. (2010) Do breakfast skipping and breakfast type affect energy intake, nutrient intake, nutrient adequacy, and diet quality in young adults? NHANES 1999-2002. J Am Coll Nutr 29, 407-418.

13. Christoforidis A, Batzios S, Sidiropoulos H et al. (2011) The profile of the Greek 'XXL' family. Public Health Nutr 14, 1851-1857.

14. Fernández San Juan PM (2006) Dietary habits and nutritional status of school aged children in Spain. Nutr Hosp 21, 374-378.

15. Kerver JM, Yang EJ, Obayashi S et al. (2006) Meal and snack patterns are associated with dietary intake of energy and nutrients in US adults. J Am Diet Assoc 106, 46-53.

16. Fernández Morales I, Aguilar Vilas MV, Mateos Vega CJ et al. (2008) Relation between the breakfast quality and the academic performance in adolescents of Guadalajara (Castilla-La Mancha). Nutr Hosp 23, 383-387.

17. Dubois L, Girard M, Potvin Kent M et al. (2009) Breakfast skipping is associated with differences in meal patterns, macronutrient intakes and overweight among pre-school children. Public Health Nutr 12, 19-28.

18. Martínez AB, Caballero-Plasencia A, Mariscal-Arcas M et al. (2010) Study of nutritional menus offered at noon school in Granada. Nutr Hosp 25, 394-399.

19. Kukulu K, Sarvan S, Muslu L et al. (2010) Dietary habits, economic status, academic performance and body mass index in school children: a comparative study. J Child Health Care 14, 355-366.

20. Ni Mhurchu C, Turley M, Gorton D et al. (2010) Effects of a free school breakfast programme on school attendance, achievement, psychosocial function, and nutrition: a stepped wedge cluster randomised trial. BMC Public Health 10, 738.

21. Eilat-Adar S, Koren-Morag N, Siman-Tov M et al. (2011) School-based intervention to promote eating daily and healthy breakfast: a survey and a case-control study. Eur J Clin Nutr 65, 203-209.

22. Mariscal-Arcas M, Romaguera D, Rivas A et al. (2007) Diet quality of young people in southern Spain evaluated by a Mediterranean adaptation of the Diet Quality IndexInternational (DQI-I). BrJ Nutr 98, 1267-1273.

23. Romaguera D, Bamia C, Pons A et al. (2009) Food patterns and Mediterranean diet in western and eastern Mediterranean islands. Public Health Nutr 12, 1174-1181.

24. Velasco J, Mariscal-Arcas M, Rivas A et al. (2009) Assessment of the diet of school children from Granada and influence of social factors. Nutr Hosp 24, 193-199.

25. Martínez E, Llull R, Del Mar Bibiloni M et al. (2010) Adherence to the Mediterranean dietary pattern among Balearic Islands adolescents. Br J Nutr 103, 1657-1664.

26. Bibiloni MM, Martinez E, Llull R et al. (2010) Prevalence and risk factors for obesity in Balearic Islands adolescents. Br J Nutr 103, 99-106. 
27. Mariscal-Arcas M, Velasco J, Monteagudo C et al. (2010) Comparison of methods to evaluate the quality of the Mediterranean diet in a large representative sample of young people in Southern Spain. Nutr Hosp 25, 1006-1013.

28. Dapcich V, Salvador Castell G, Ribas Barba L et al. (2004) Guía de la alimentación saludable. Madrid: Sociedad Espanola de Nutrición Comunitaria.

29. Moreiras O, Carbajal A, Cabrera L et al. (2007) Tablas de composicion de alimentos, 11th ed. Madrid: Piramide.

30. Jiménez Cruz A, Cervera Ral P \& Bacardi Gascón M (2001) NOVARTIS-Dietsource v 1.2. (C) 0105071807 .

31. Trichopoulou A, Costacou T, Christina B et al. (2003) Adherence to a Mediterranean diet and survival in a Greek population. New Engl J Med 348, 2599-2608.

32. Tur JA, Romaguera D \& Pons A (2004) Adherence to the Mediterranean dietary pattern among the population of the Balearic Islands. Br J Nutr 92, 341-346.

33. Mariscal-Arcas M, Rivas A, Velasco J et al. (2009) Evaluation of the Mediterranean Diet Quality Index (KIDMED) in children and adolescents in Southern Spain. Public Health Nutr 12, 1408-1412.

34. De Rufino Rivas P, Redondo Figuero C, Amigo Lanza T et al. (2005) Breakfast and snack of schooled adolescents in Santander. Nutr Hosp 20, 217-222.

35. Alexy U, Wicher M \& Kersting M (2010) Breakfast trends in children and adolescents: frequency and quality. Public Health Nutr 13, 1795-1802.

36. Moreno LA, Rodriguez G, Fleta J et al. (2010) Trends of dietary habits in adolescents. Crit Rev Food Sci Nutr 50, 106-112.

37. Serra-Majem L, Ribas L, Ngo J et al. (2004) Food, youth and the Mediterranean diet in Spain. Development of KIDMED, Mediterranean Diet Quality Index in children and adolescents. Public Health Nutr 7, 931-935.

38. Lazarou C, Panagiotakos DB, Kouta C et al. (2009) Dietary and other lifestyle characteristics of Cypriot school children: results from the nationwide CYKIDS study. BMC Public Health 20, 147.

39. Goglia R, Spiteri M, Ménard C et al. (2010) Nutritional quality and labelling of ready-to-eat breakfast cereals: the contribution of the French observatory of food quality. Eur J Clin Nutr 64, Suppl. 3, S20-S25.

40. López-Miranda J, Pérez-Jiménez F, Ros E et al. (2010) Olive oil and health: summary of the II international conference on olive oil and health consensus report, Jaén and Córdoba (Spain) 2008. Nutr Metab Cardiovasc Dis 20, 284-294.

41. Gillingham LG, Harris-Janz S \& Jones PJ (2011) Dietary monounsaturated fatty acids are protective against metabolic syndrome and cardiovascular disease risk factors. Lipids $\mathbf{4 6}$, 209-228.

42. Carrillo Fernández L, Dalmau Serra J, Martínez Álvarez JR et al. (2011) Dietary fats and cardiovascular health. An Pediatr (Barc) 74, 192.e1-192.e16.

43. Gaskins AJ, Rovner AJ, Mumford SL et al. (2010) Adherence to a Mediterranean diet and plasma concentrations of lipid peroxidation in premenopausal women. Am J Clin Nutr $\mathbf{9 2}$, $1461-1467$.

44. Ambroszkiewicz J, Klemarczyk W, Gajewska J et al. (2010) The influence of vegan diet on bone mineral density and biochemical bone turnover markers. Pediatr Endocrinol Diabetes Metab 16, 201-204.

45. Rafferty K, Watson P \& Lappe JM (2011) The selection and prevalence of natural and fortified calcium food sources in the diets of adolescent girls. J Nutr Educ Behav 43, 96-102.

46. Vissers PA, Jones AP, Corder K et al. (2011) Breakfast consumption and daily physical activity in 9-10-year-old British children. Public Health Nutr (Epublication ahead of print version).

47. Foster-Powell K, Holt SH \& Brand-Miller JC (2002) International table of glycemic index and glycemic load values. Am J Clin Nutr 76, 5-56.

48. Van Cauter E, Blackman JD, Roland D et al. (1991) Modulation of glucose regulation and insulin secretion by circadian rhythmicity and sleep. J Clin Invest 88, 934-942.

49. Westenhoefer J (2006) Carbohydrates and cognitive performance. Aktuelle Ernaehrungsmedizin 31, Suppl. 1, S96-S102.

50. World Health Organization (2002) Joint WHO/FAO Expert Consultation on Diet, Nutrition and the Prevention of Chronic Diseases. Geneva: WHO.

51. Clark C \& Crockett SJ (2008) Concern over ready-to-eat breakfast cereals. J Am Diet Assoc 108, 1618-1619; author reply $1619-1620$.

52. Harris JL, Schwartz MB, Ustjanauskas A et al. (2011) Effects of serving high-sugar cereals on children's breakfast-eating behavior. Pediatrics 127, 71-76.

53. Smith MA \& Foster JK (2008) The impact of a high versus a low glycaemic index breakfast cereal meal on verbal episodic memory in healthy adolescents. Nutr Neurosci 11, 219-227.

54. Pearson N, Atkin AJ, Biddle SJ et al. (2010) Parenting styles, family structure and adolescent dietary behaviour. Public Health Nutr 13, 1245-1253.

55. Basch CE (2001) Breakfast and the achievement gap among urban minority youth. J Sch Health 81, 635-640. 